\title{
The Impact of Some Socio-Economic Factors on Academic Performance: A Fuzzy Mining Decision Support System
}

\author{
Olufunke O. Oladipupo*1 and Amenawon I. Ehigbochie ${ }^{1}$ \\ ${ }^{1}$ Department of Computer Science, College of Science and Technology, Covenant \\ University, Ota, Ogun State, Nigeria \\ funke.oladipupo@covenantuniversity.edu.ng, \\ amenawon.ehigbochie@covenantuniversity.edu.ng
}

\begin{abstract}
Due to the reported impacts of some socio-economic factors on academic performance and nations' education value, there is need for strong awareness to assist students in making the right decision. To this effect, this study proposes and designs student decision support system for determining the extent to which different levels of some socioeconomic factors involvement can jointly affect academic performance. The factors are: Student's interest, Relationship status, Entrepreneurial activities, Peer influence, Health and family background. The traditional decision support system architecture was extended in this study by introducing two components: Fuzzy engine and Mining Engine. Fuzzy engine was introduced to capture intra uncertainties in students' judgment about the data gathered and Mining engine to extract hidden and previously unknown interesting patterns from the dataset. The predictive model was established using fuzzy association rule mining technique. The dataset was gathered using one-on-one questionnaire interaction with students from 4 Universities in Nigeria. The system evaluates students' linguistic levels of involvement and predicts the possible class of honours for them with explicit interpretation of the fired patterns. This system will assist the students in decision making as to the extent they can be involved in some socioeconomic activities relative to their family and health status in order to have their desired classes of honour.
\end{abstract}

Keywords: Students' academic performance, Socio-economic factors, Decision Support System, Fuzzy Association Rule mining

\section{Introduction}

Education is germane to individual, economic, social and cultural development. It is a catalyst for positive societal change. Therefore, academic performance can be defined as an outcome of education, the degree to which a student has attained the institutional objectives [1]. The most significant assets of any university are the students; therefore, the nature and standard of a university are determined by the academic performances of the students [1].Academic performance has been recognized as a weighing scale for checking the mental capabilities and abilities of students. It is the reflector of the educational set up of a country [2]. The academic performance shows students' levels of skill, knowledge and identity; personal efforts, fixed factors and more. Good academic performance is an outcome of sound education and produces good outcomes that could improve students' value, exempt students from criminal activities, open the students to huge opportunities, reduce menace, and give the students better self-esteem in the society. Therefore, the priority of every parent and student is sound education, leading to good academic performance. 
Nevertheless, many students are still struggling to attain good academic grades while some are finding it difficult to maintain their achieved grades. From the literature there are many factors that may be responsible for this, among which socio-economic factors have been frequently highlighted [3],[4] and[5]. This suggests the need for a proper awareness of such socio-economic factors and the extent of their effects on students' academic performance. A decision support system is a domain specific computerized information system that supports decision making in a particular area [6]. Therefore, availability of a decision support system will enable the students to take the right decision about their involvement in such socio-economic factors. To this effect, in this study, a student decision support system is proposed for proper awareness of the joint effect of some socio-economic factors on students' academic performance. The system is established on Data mining techniques to extract hidden and previously unknown interesting knowledge from data. Also, the system was enhanced with fuzzy concept so as to capture intra uncertainties of the domain expert in the study. The remaining parts of the paper are as follows: section two provides a review of decision support system and related works, Section 3 explains the proposed system, while the proposed system was validated and evaluated in Section 4 and 5 respectively. The paper is concluded in Section 6.

\section{Literature Review}

\subsection{Decision Support System}

Decision Support System (DSS) is a computer-based information system that reasons through stored or online knowledge from existing data or domain experts to provide alternative decisions for decision makers [7]. It is a domain specific computerized information system that supports decision making in a particular area [6]. Based on the various definitions, a DSS can be summarized as a way of modelling data and making informed decisions from it. The required knowledge is acquired into the knowledge-based in form of rules for inferencing purpose. However, the quality of the decisions depends largely on the quality of knowledge acquired, the method and the data analyzed to extract the knowledge. A typical DSS is composed of several components as shown in Figure 1.

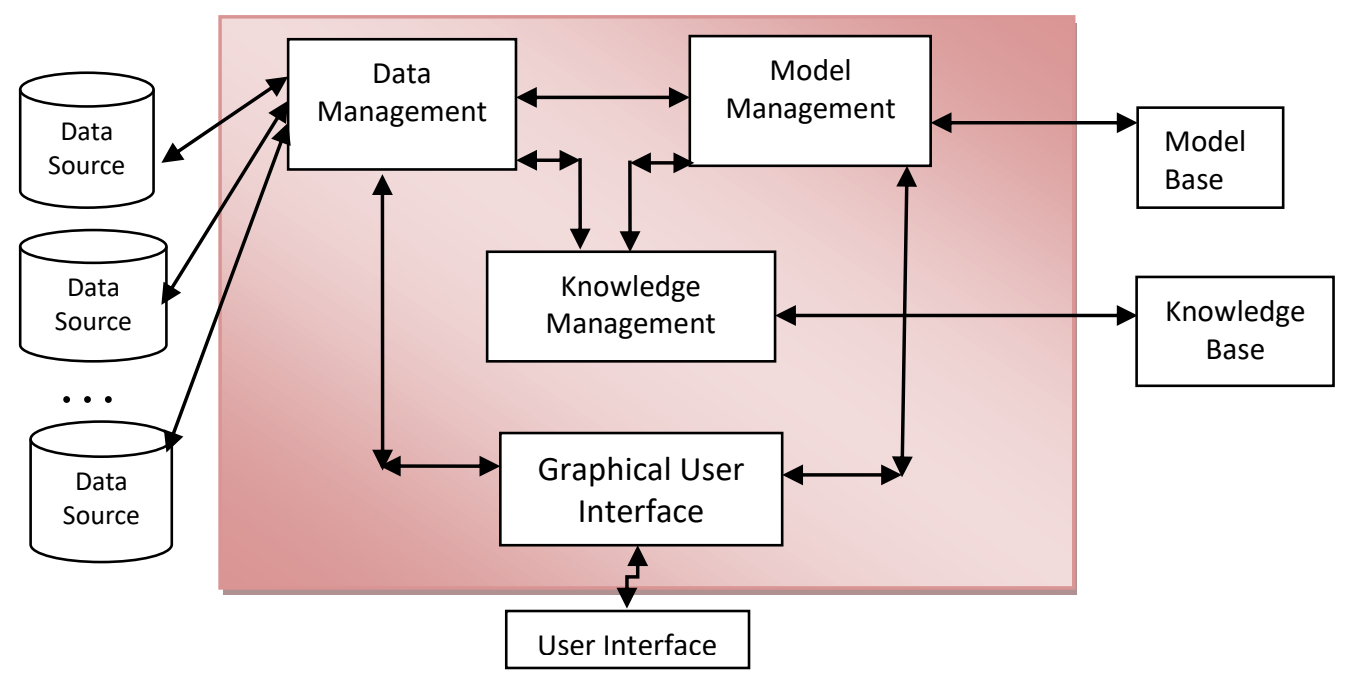

Figure 1. A Typical Decision Support System [8] 


\subsection{Related Works}

From the literature, it was observed that lots of research have been conducted on factors that affect academic performance which include socio-economic factors [9], [10] and [11]. Among other factors, the effect of socio-economic factors on students' academic performance has really gained prominence. Socio-economic status has been expressed from different perspectives in the literature since there is no accepted conceptual meaning for it [12]. In [13] Socio-economic status was described as a family or individual ranking based on their access level to or control over some combination of valued commodities such as wealth, power and social status. From a social point of view, it was described in [14] as a high quality work force, equal opportunity, social development of civil awareness and community attainment. Also, economically, it is seen as innovation and the ability to increase the country's economic power. In [15] socio-economic status of a student was described as a factor that could determine the secondary school a student can attend, influence the chances of being accepted in the University and the potential income earning in life. In order to analyse and create proper awareness on the effect of some socio-economic factors on students' academic performance a lot has been presented in the literature.

In [9] how socio-economic factors influence students' academic performance in Nigeria was analysed statistically using t-test. The analysis was based on parental income, family type, lack of funding, home background, learning environment, poverty and government policies. Also, [11] carried out a statistical analysis on the impact of socioeconomic factors on students' academic performance. In this work, a canonical correlation and multiple regression analysis methods were used. The student's CGPA was used as dependent variable and parental background, hostel facilities, peer group, students' health, students' attitude to studies, educational resource available, sport activities, students' enrolment and lecturers' teaching method group were used as independent variables. Also, [5] reported the impact of Students' socio-economic background on academic performance in Universities, using a case study of Students in Kisii University College. A proportional sampling method which targeted both male and female students of Kisii University College was used. It was reported that students' inability to afford good residential rooms, catering facilities and recreational facilities was based on their socio-economic status and this had adverse effects on their academic performance.

In [16] the influence of family structure on students' academic performance was reported, using students within Agege Local Government secondary schools, Lagos State, Nigeria as a case study. Multivariate analysis approach was applied to determine the influence of family structure and parental socio-economic status on academic performance of students. Results demonstrated that academic performance of students from single-guardian families and that of their partners from two-guardian families do not vary, as students from single parent competed and performed better than their counterparts from two-guardian families in Nigeria. The t-test statistical analysis was employed in testing the hypotheses at 0.05 level of significance. In [18] a study was carried out on factors influencing students' academic performance using Naïve Bayesian algorithm, MLP, SMO, J48, REP tree, RANDOM tree and Decision table. The instances were classified based on probabilities. The focus was on students' community, religion, living area and department; parents' qualification, fathers' occupation and more. [19] also examined some factors affecting academic achievement of undergraduate students in international program. Two classification algorithms were adopted and compared. The classification models were implemented using WEKA 3.7.5 version.

Also, the effects of some other factors on students' academic performance have been well reported in the literature. In [4] the impact of attendance on students' academic performance in information and communications technology (ICT) related courses, a case study of Faculty of Engineering, Osun State Polytechnic, Iree, was reported. The analysis 
was carried out with statistical approach using regression and Correlation analyses. The result showed that attendance in class had positive impact on students' academic performance without specifying the extent. In [3] a data mining approach was introduced to investigate the effect of class attendance on students' academic performance using association rule mining technique. The result shows the extent, in percentage, to which the class attendance can affect students' academic performance.

Despite the awareness in literature, lots of students have not been able to overcome the challenges posed by their academic performance. This has become a major issue of concern to managements of institutions. Obviously, students are faced with lots of uncertainties in their choice of academic decisions and social involvements. In order to support their decisions appropriately, there is need for supporting systems to help identify those factors that affect their academic performance and the extent. This will enable individuals to balance their involvements in order to enhance their academic performance. Another important concern from literature is that most of the analyses on socio-economic factors were based on statistical analysis. This is not sufficient to extract unknown, hidden and useful patterns from the data set that could assist the students in making impactful decisions. These concerns call for urgent measures that will foster growth, willingness, and motivation in the various levels of development of the students' life; increase the momentum of students to study and create a platform that could help them prioritize and come up with informed decisions. Hence, the need for a student decision support system based on data extraction approach and which stems from the effect of socio-economic factors on students' academic performance. This can support the students in making the right decisions relating to their involvement in some factors that can affect their academic pursuit adversely.

To realize this, data mining has proved to be effective in discovering hidden, interesting and useful knowledge in educational database [20]. Data mining allows data to be viewed from different perspectives and users can communicate with data effectively. Furthermore, making decisions from data is more realistic because of the patterns that are discovered by data mining techniques. This has made Data mining an important development in database technology. A pattern is considered interesting if (1) it is easily understood by humans, (2) it has enough level of significance, (3) it is relative to the expected result and validates the hypothesis the user sought to confirm, and (4) it represents knowledge [21]. Therefore, this study proposes and designs a fuzzy student decision support system for determining the extent to which some socio-economic factors can jointly affect academic performance. The predictive model for the system was established using fuzzy association rule mining technique to extract hidden and previously unknown interesting data and capture the intra uncertainties in the dataset.

\section{The Proposed System}

The proposed system enhances the Traditional Decision Support System [8] by adding two new components to the architecture which are: Fuzzy Engine and Mining Engine. The fuzzy engine is incorporated in order to capture the intra-uncertainty in the domain expert judgment. The Mining engine is used to extract hidden and previously unknown interesting knowledge from the dataset gathered in order to acquire the knowledge-base. The system architecture is composed of seven main components as shown in Figure 2. The additional components are indicated with a dotted box.

From different sources, data are gathered for the decision support system using a reliable Database Management System. The Model management is where models are constructed, managed and stored in a model base. Traditionally, based on the constructed models, the database is transformed into knowledge which is stored in the knowledge base for appropriate inferencing process. In this study, fuzzy models are constructed based on the data description and domain expert knowledge. The crisp dataset gathered is then 
transformed into fuzzy dataset in the fuzzy engine. The process is called fuzzification process. This is to capture the subjectiveness and intra uncertainties in the expert judgment from the questionnaire. The fuzzified dataset goes to the mining engine, from where the hidden and previously unknown interesting knowledge is extracted. Different mining techniques can be activated for this purpose depending on the system engineer and the expected inference. The knowledge is acquired directly into the knowledge-base for proper inference in responding to the user query via the GUI interface.

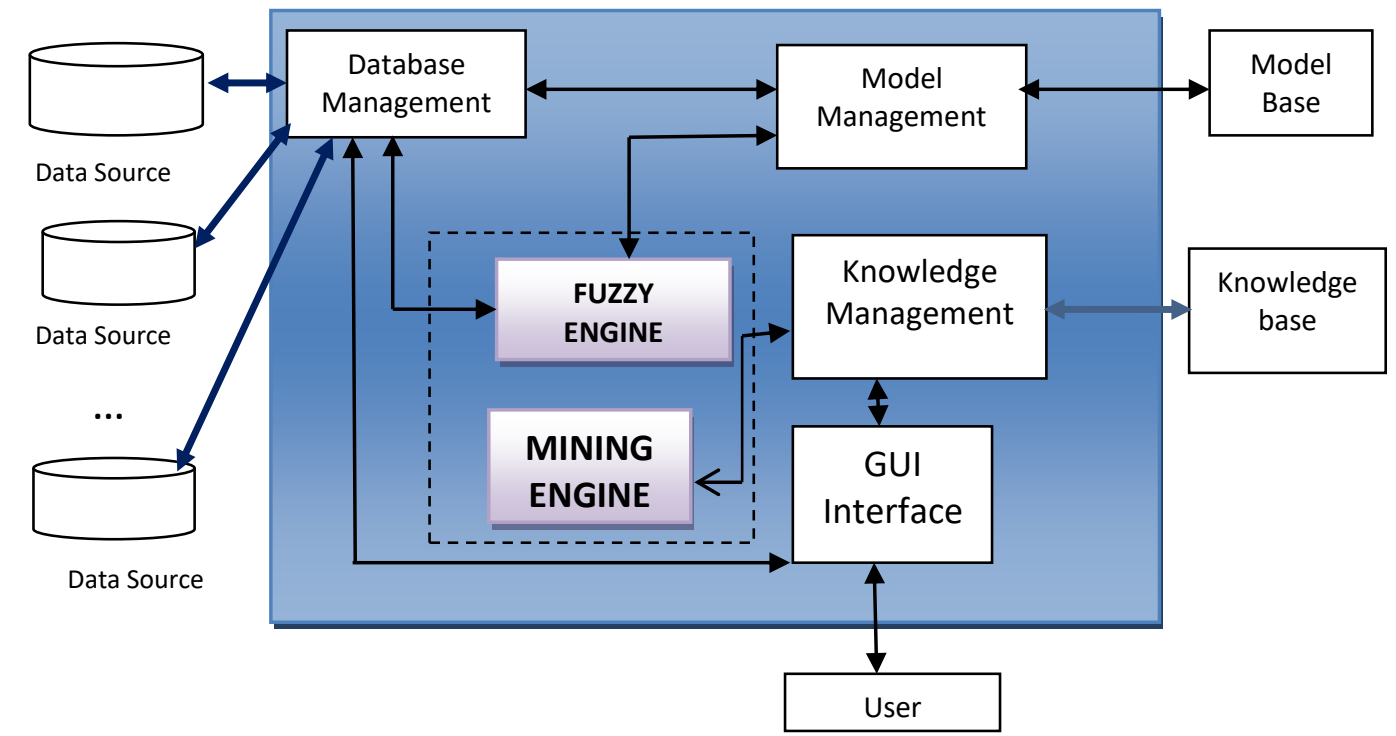

Figure 2. Proposed Architecture of a Fuzzy Mining Student Decision Support System

\section{System Validation}

\subsection{Data Source}

The domain experts used in this research work were 200 level students and above. These samples comprised both males and females from four different universities in Nigeria. Based on their experience of the factors, they were able to provide the data required. More than 3,000 questionnaires were distributed, out of which 2635 were returned; from which 2535 records were used, which amounted to $96.2 \%$. The remaining 100 records were voided because of incompleteness and unrealistic nature of the data collected. This represented 3.8\% of the dataset. The dataset consists of 2535 record, with 7 attributes. 6 of the attributes are input attributes (Student Interest, Entrepreneurial Involvement, Peer Influence, Family Background, Marital Status, and Health Condition) while one is output attribute (CGPA).

\subsection{Research Instrument}

The research instrument used for data gathering was questionnaire. The questionnaire was constructed after a careful review of the literature and interaction with the experts. It contained information that captured students' age, sex, CGPA, interest, entrepreneurial involvement, peer influence, family background, marital status and health condition. The questionnaire was made up of seven items covering the socio-economic factors under investigation. Six of the attributes were input attributes and one output attribute (CGPA). Five questions were considered to reflect the importance of each attribute.

The reliability of the questionnaire was determined by Cronbach alpha statistics. It determines internally correlated constituents of items to see if they are measuring in the 
same domain. It is expressed as a number between 0 and 1 [22]. The result shows that out of the 30 items (see Appendix1), 23 of the factors best predict the reliability of the questionnaire. The Results show that if any of the following items; 6, 7, 10, 11, 15, 30 is deleted the reliability of the questionnaire will increase; while, if any of the remaining 23 items is deleted, the reliability of the questions will be low. Therefore, considering the remaining 23 items, the questionnaire is reliable at 0.701 ( $p>0.64)$.

The Students' responses are in five categories: Strongly Agree (SA), Agree (A), Undecided (U), Disagree (D), and Strongly Disagree (SD). To assign a Crisp value to each response, a five point Likert scale was used; values were assigned according to how the question has impacted on the factors as related to the research analysis. For instance, a positive impact question was assigned 10 points for strongly agree, and for negative impact questions 0 was assigned. Table 1 shows the Questionnaire attributes response value rating. To get the crisp value for a particular attribute, aggregate sum model was used to acquire quantitative values for each factor as represented in equation (1). A typical example is shown in Table 2 and the student's response is identified with " $X$ ".

$$
\mathrm{A}=. \quad \sum_{i=1}^{m} x_{i} \quad \text { Where } x_{i} \text { represents each facto }
$$

Table 1. Questionnaire Attributes Response Value Rating

\begin{tabular}{|c|c|c|}
\hline Factors & Response & Value \\
\hline \multirow{5}{*}{ Interest } & Strongly Agree & 0 \\
\hline & Agree & 2 \\
\hline & Undecided & 5 \\
\hline & Disagree & 8 \\
\hline & Strongly Disagree & 10 \\
\hline \multirow{5}{*}{$\begin{array}{l}\text { Entrepreneurial } \\
\text { Involvement }\end{array}$} & Strongly Agree & 10 \\
\hline & Agree & 8 \\
\hline & Undecided & 5 \\
\hline & Disagree & 2 \\
\hline & Strongly Disagree & 0 \\
\hline \multirow[t]{5}{*}{ Family Background } & Strongly Agree & 10 \\
\hline & Agree & 8 \\
\hline & Undecided & 5 \\
\hline & Disagree & 2 \\
\hline & Strongly Disagree & 0 \\
\hline \multirow[t]{5}{*}{ Peer Influence } & Strongly Agree & 0 \\
\hline & Agree & 2 \\
\hline & Undecided & 5 \\
\hline & Disagree & 8 \\
\hline & Strongly Disagree & 10 \\
\hline \multirow[t]{5}{*}{ Relationship } & Strongly Agree & 0 \\
\hline & Agree & 2 \\
\hline & Undecided & 5 \\
\hline & Disagree & 8 \\
\hline & Strongly Disagree & 10 \\
\hline \multirow[t]{5}{*}{ Health Condition } & Strongly Agree & 0 \\
\hline & Agree & 2 \\
\hline & Undecided & 5 \\
\hline & Disagree & 8 \\
\hline & Strongly Disagree & 10 \\
\hline
\end{tabular}


Table 2. Aggregate Sum Of Factors Based On The Interest Of A Student

\begin{tabular}{|l|l|l|l|l|l|}
\hline INTEREST & SA (0) & $\begin{array}{l}\text { A } \\
(2)\end{array}$ & U (5) & $\begin{array}{l}\text { D } \\
(8)\end{array}$ & SD (10) \\
\hline I am interested in schooling or education in general & $\mathrm{X}$ & & & & \\
\hline I love my course & & $\mathrm{X}$ & & & \\
\hline I am active in class & & & $\mathrm{X}$ & & \\
\hline I love being in class & & & & & $\mathrm{X}$ \\
\hline I chose this course myself & & & $\mathrm{X}$ & & \\
\hline
\end{tabular}

Based on this response, Aggregate sum was used to get the crisp value.

$$
\mathrm{A}=\sum_{i=1}^{m} x_{i}=0+2+5+10+5=22 \text {. }
$$

Therefore, 22 is the crisp interest value for this particular student. For each attribute the maximum value is 50 and the minimum is 0 . All input attributes values (rule antecedent) are partitions following the ranges in Table 3(a) and the output attribute values (rule consequent) is partition as in Table 3(b).

Table 3. Range Partitioning for the Attributes

\begin{tabular}{|c|l|}
\hline Socio-econimic Factor value & Linguistic Term \\
\hline$<\mathbf{2 5}$ & Low \\
\hline $\mathbf{2 5}-\mathbf{3 4}$ & Average \\
\hline $\mathbf{3 5}-\mathbf{5 0}$ & High \\
\hline
\end{tabular}

(a)

\begin{tabular}{|l|l|}
\hline CGPA & Linguistic Term \\
\hline $\mathbf{4 . 5} \leq G \leq 5$ & Cgpa 1 \\
\hline 3.5. $\leq$ G $\leq 4.5$ & Cgpa21 \\
\hline $\mathbf{2 . 5} \leq G \leq 3.5$ & Cgpa22 \\
\hline $\mathbf{1 . 5} \leq G \leq 2.5$ & Cgpa3 \\
\hline
\end{tabular}

(b)

\subsection{Database and Model Management}

XAMPP 1.7.7 Mysql, as the Database Management System (DBMS), was used to store the students' records. All processed data output were all stored with the DBMS. The model base of the system carries the analytical capability of the system and houses the models used. The fuzzy models for fuzzification process was based on triangular membership function because of the nature of the data. For all antecedent variables, which are Interest, entrepreneur, family background, peer influence and relationship, the fuzzy sets are; \{low, average, High $\}$. For each fuzzy set the membership grade expression was determined using triangular membership function (trimf). For all the input variables the expressions are similar, based on domain experts' and the knowledge engineers' description of the data. Therefore, the sample fuzzy model for interest attribute is shown in equation (2-4). For the consequent variable: cumulative grade point, the fuzzy expressions were also based on triangular membership function as shown in equation (58) 


$$
\begin{gathered}
\mu_{\text {int }}(\text { Low })=\left\{\begin{array}{cc}
1 & \text { if } x \leq 20 \\
\frac{30-x}{10} & \text { if } 20 \leq x \leq 30
\end{array}\right. \\
\mu_{\text {int }}(\text { Ave })= \begin{cases}\frac{x-20}{10} & \text { if } 20 \leq x \leq 30 \\
1 & \text { if } 30 \leq x \leq 35 \\
\frac{45-x}{10} & \text { if } 35 \leq x \leq 45\end{cases} \\
\mu_{\text {int }}(\text { High })= \begin{cases}\frac{x-45}{10} \text { if } 3 \leq x \leq 45 \\
1 \quad \text { if } 45 \leq x \leq 50\end{cases}
\end{gathered}
$$

Where $\mathrm{x}$ is the crisp aggregate quantitative evaluation of each student's academic interest based on the questionnaire.

$$
\begin{gathered}
\mu_{\text {GPA1 }}(g)=(2 \times g)-9 \\
\mu_{\text {GPA21 }}(g)=\left(\frac{g}{0.99}\right)-3.54 \\
\mu_{\text {GPA22 }}(g)=\left(\frac{g}{0.99}\right)-2.53 \\
\mu_{\text {GPA }}(g)=\left(\frac{g}{0.99}\right)-1.52
\end{gathered}
$$

Where $\mathrm{g}$ is the student's CGPA quatitative measure as of the last semester prior to the evaluation.

\subsection{Fuzzification Process}

This process takes place in the fuzzy engine. For fuzzification process each attribute fuzzy set was determined as shown in Table 4. The membership models formulated were implemented with Java NetBeans programming language. The output from this process is a fuzzified table which is the input to the next stage of the process. The snapshot of the crisp dataset in the DBMS is shown in Figure 3. Also, the Java NetBeans snapshot for fuzzification process is shown in Figure 4.

Table 4. Fuzzification of Linguistic Variables

\begin{tabular}{|l|l|l|}
\hline Linguistic Variables & $\begin{array}{l}\text { Variable } \\
\text { domain }\end{array}$ & Fuzzy Sets \\
\hline Interest & Input & \{intlow, intAve, intHigh $\}$ \\
\hline Entrepreneurial Involvement & Input & \{entlow, entAve, entHigh $\}$ \\
\hline Family Background & Input & $\{$ fblow, fbAve, fbHigh $\}$ \\
\hline Peer Influence & Input & \{pillow, piAve, piHigh $\}$ \\
\hline Relationship & Input & \{rellow, relAve, relHigh $\}$ \\
\hline Health Condition & Input & $\{$ hclow, hcAve, hcHigh $\}$ \\
\hline CGPA & Output & \{CGPA1,CGPA21,CGPA22,CGPA3 $\}$ \\
\hline
\end{tabular}




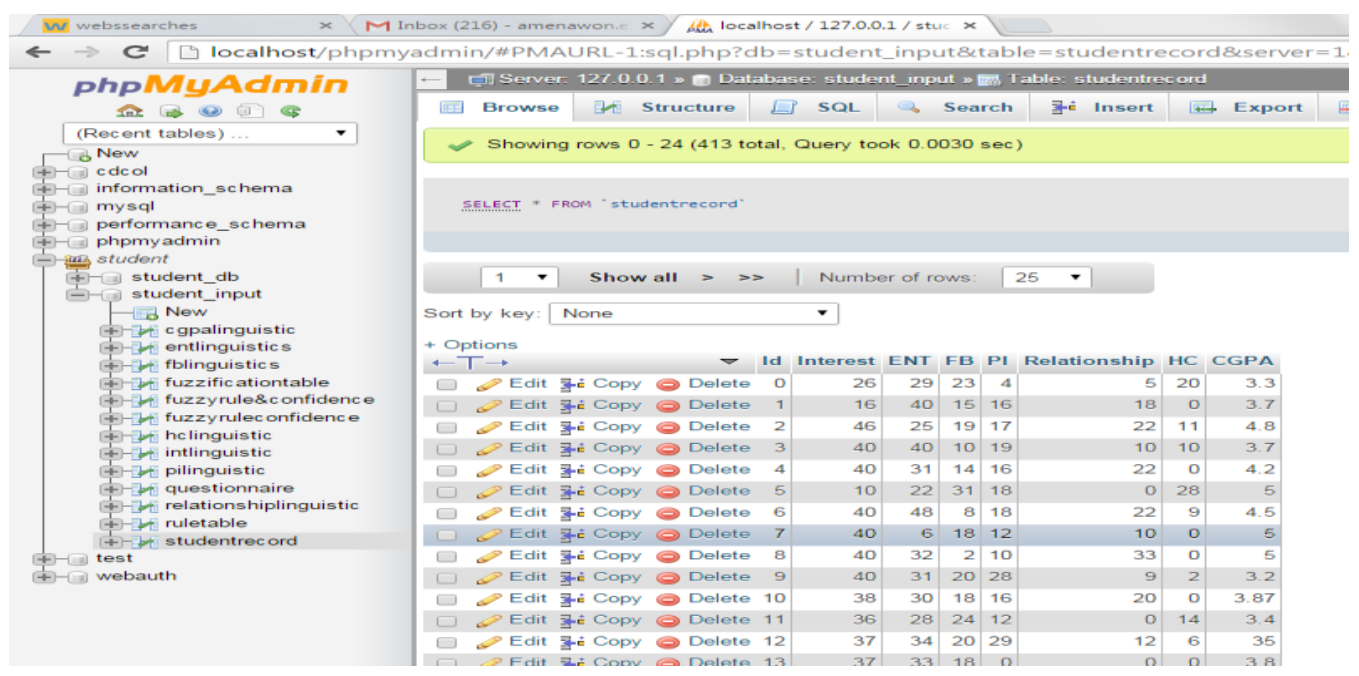

Figure 3. Crisp Data Set from Database

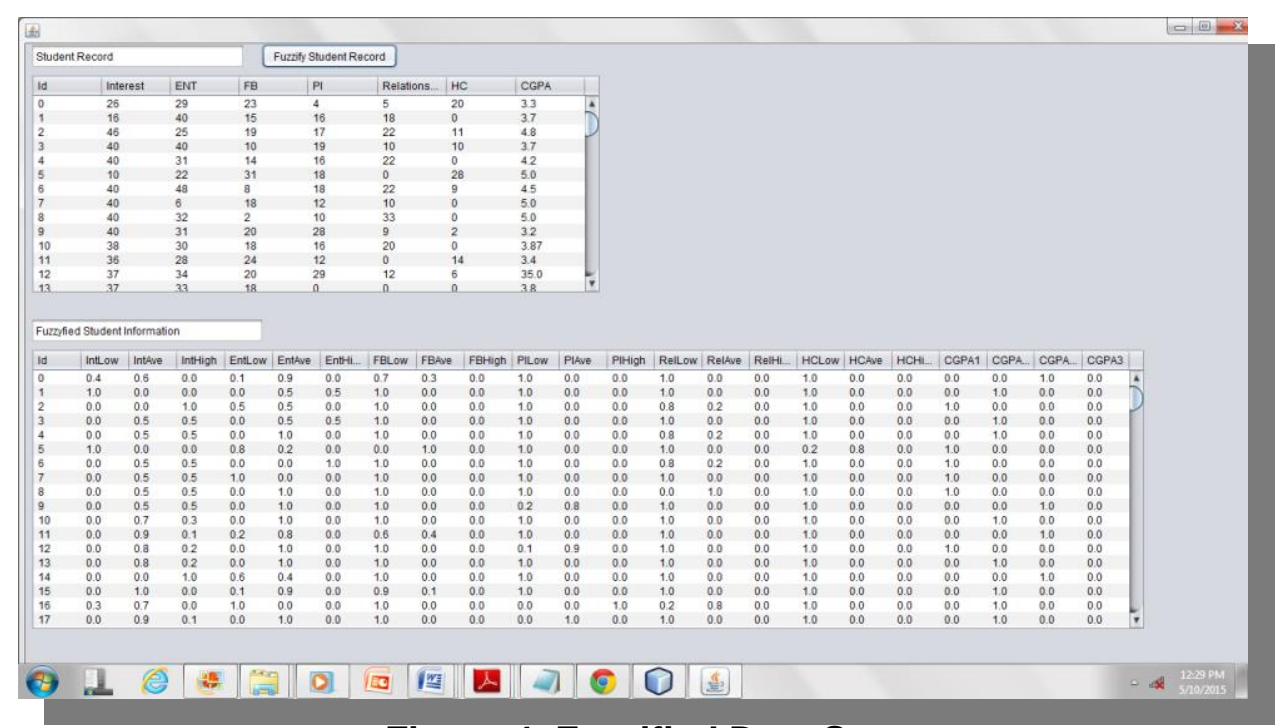

Figure 4. Fuzzified Data Set

\subsection{Mining Process}

For the mining process, Association Rule Mining Technique was considered to determine the relationship between the input variables and the output variable. Apriorilike Fuzzy association rule mining algorithm in Figure 5 was adopted since the mining process is for fuzzy dataset. The algorithm was implemented using Java NetBeans programming language because it possesses the features for implementing the algorithm and also enhances a user friendly interface. For a rule to be considered interesting it should have enough level of certainty and significance. The input for the process is the fuzzy data set, the outputs from the mining process are numbers of patterns in form of rules. The minimum significant factor and certainty factor threshold used is 0.0 , so as to capture maximum number of possible rules in order to enhance the decision support system completeness. The implication is that if any rule does not have significant value and certainty value greater than zero, such rule is not interesting. A sample output is shown in Figure 6 


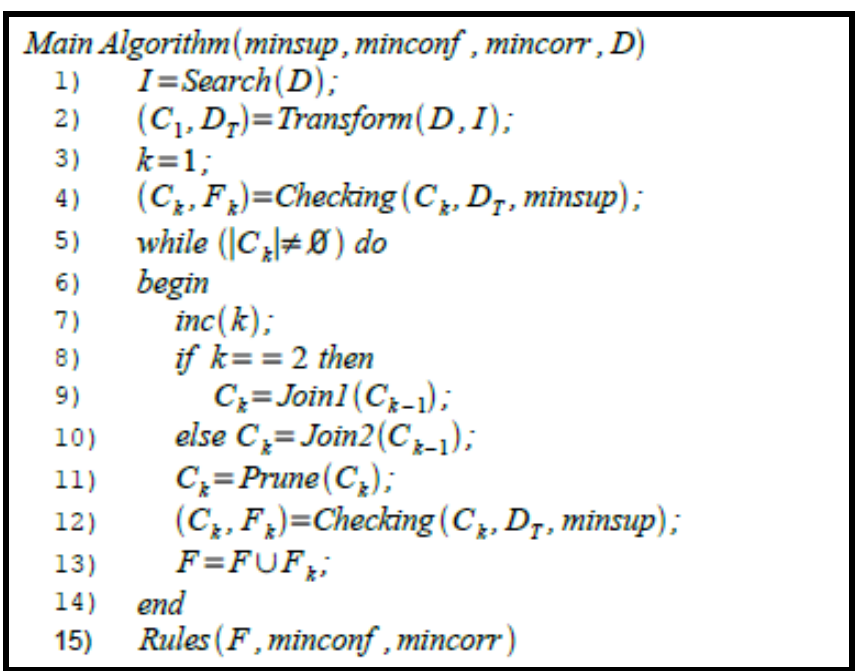

Figure 5. Apriori -Like Fuzzy Association Rule Mining Algorithm [21]

\begin{tabular}{|c|c|c|c|c|c|}
\hline No. Of. Rules & 2916 & & & & \\
\hline & RecordNo & $\begin{array}{r}\text { Rule } \\
\end{array}$ & & & Confidence \\
\hline 0 & & intLow,entLow, foLow,piLow,rellow, hcLow->cgpa1 & 99.8 & 13.6 & \\
\hline 1 & & intAve,entLow, foLow,piLow,rellow,hcLow->cgpa1 & 99.7 & 13.5 & \\
\hline 2 & & inthigh,entLow, foLow,pilow,relLow,hcLow->cgpa1 & 99.8 & 13.5 & \\
\hline 3 & & intLow,entAve, folow,piLow,rellow,hcLow->cgpa1 & 99.7 & 13.6 & \\
\hline 4 & & intAve,entAve, foLow,piLow,rellow,hcLow->cgpa1 & 99.7 & 13.5 & \\
\hline 5 & & intHigh,entAve, foLow,piLow,rellow,hLLow->cgpa1 & 99.7 & 13.4 & \\
\hline 6 & & intLow,enthigh, foLow,pilow,relLow,hcLow->cgpa1 & 99.9 & 13.5 & \\
\hline 7 & & intAve,enthigh, folow,piLow,rellow,hcLow->cgpa1 & 99.9 & 13.5 & \\
\hline 8 & & inthigh,enthigh, foLow,pilow,rellow,hcLow->cgpa1 & 99.9 & 13.4 & \\
\hline 9 & & intLow,entLow, fDAve, piL Low,relLow,hcLow->cgpa1 & 99.5 & 13.6 & \\
\hline 10 & & intAve,entLow, foAve,piLow,rellow, ,cLow->cgpa1 & 99.2 & 13.5 & \\
\hline 11 & & inthigh,entLow, foAve, piLow,rellow,hcLow->cgpa1 & 99.6 & 13.5 & \\
\hline 12 & & intLow, entAve, fbAve,piLow,rellow,ncLow->cgpa1 & 99.5 & 13.6 & \\
\hline 13 & & intAve,entAve, foAve,piLow,relLow,hLLow->cgpa1 & 99.4 & 13.5 & \\
\hline 14 & & inthigh,entAve, foAve,pilow,rellow,hcLow->cgpa1 & 99.8 & 13.4 & \\
\hline 15 & & intLow,enthligh, foAve, piLow,rellow,hcLow->cgpa1 & 99.4 & 13.5 & \\
\hline 16 & & intAve, enthigh, ffave,piLow,relLow,hcLow->cgpa1 & 99.1 & 13.5 & \\
\hline 17 & & inthigh,enthigh, foAve,pilow,relLow,hcLow-scgpa1 & 99.5 & 13.4 & \\
\hline 18 & & intLow,entLow, foHigh,pilow,rellow,hcLow->cgpa1 & 99.2 & 13.6 & \\
\hline 19 & & intAve,entLow, foHigh,pilow,rellow,ncLow->cgpa1 & 99.0 & 13.5 & \\
\hline 20 & & intligh,entLow, fotigh,piLow,relLow,hcLow->cgpa1 & 99.5 & 13.5 & \\
\hline
\end{tabular}

Figure 6. Fuzzy Association Rules

\subsection{Knowledge-Base}

The extracted rules from the mining process were transformed into a relational structure. 2916 rules were extracted from the mining process and stored in the knowledge-base for appropriate inferencing by the decision support system. These rules represent all possible involvement of students in the six socio-economic factors considered. The Snapshot of some of the Extracted Rules is shown in Figure 7.

\subsection{Graphical User Interface}

The graphical user interface communicates between the user and the decision support system. This allows the user to interact with the decision support system by specifying their linguistic involvement in the six socio-economic factors inform of query. The output from the system based on the query is communicated as suggestions via the user interface with recommendation. An instance of the Decision Support System interaction is shown 
in Figure 8. A summary of how the fuzzy mining student decision Support system works includes:

- The student record is stored in the database after submission. Each student is identified by their ID number assigned at the point of registration.

- Students highlight their involvement from the user interface and submit to the knowledge-base.

- The query is sent to the knowledge-base to find the match.

- Based on the match, the knowledge-base fires out relevant patterns for students' decision.

- In response, the decision support system gives suggestions and recommendations which interpret the patterns in students' understandable language to inform their decisions.

\begin{tabular}{|c|c|c|c|c|c|c|c|c|}
\hline RecordNo IntLinguistic & EntLinguistic & FBLinguistic & c PlLinguistic & Rellinguistic & HCLinguistic & CGPALinguistic & Significance & Certainty \\
\hline 1 intlow & entLow & fblow & pilow & rellow & hcLow & 0.00 & 99.73 & 13.60 \\
\hline 2 intAve & entlow & fblow & pilow & rellow & hcLow & 0.00 & 99.76 & 13.59 \\
\hline 3 intHigh & entlow & fbLow & pilow & rellow & hcLow & 0.00 & 99.83 & 13.58 \\
\hline 4 intlow & entAve & fblow & pilow & rellow & hcLow & 0.00 & 99.52 & 13.63 \\
\hline 5 intAve & entAve & fblow & pilow & rellow & hcLow & 0.00 & 99.83 & 13.58 \\
\hline 6 inthigh & entAve & fblow & pilow & rellow & hcLow & 0.00 & 99.54 & 13.62 \\
\hline 7 intlow & enthigh & fblow & pilow & rellow & hcLow & 0.00 & 99.54 & 13.62 \\
\hline 8 intAve & enthigh & fblow & pilow & rellow & hcLow & 0.00 & 99.85 & 13.58 \\
\hline 9 intHigh & enthigh & fblow & piLow & rellow & hcLow & 0.00 & 99.64 & 13.61 \\
\hline 10 intlow & entLow & fbAve & pilow & rellow & hcLow & 0.00 & 99.64 & 13.61 \\
\hline 11 intAve & entlow & fbAve & pilow & rellow & hcLow & 0.00 & 99.37 & 13.65 \\
\hline 12 inthigh & entlow & fbAve & pilow & rellow & hcLow & 0.00 & 99.37 & 13.65 \\
\hline 13 intLow & entAve & fbAve & pilow & rellow & hcLow & 0.00 & 99.49 & 13.63 \\
\hline
\end{tabular}

Figure 7. Snapshot of some of the Extracted Rules

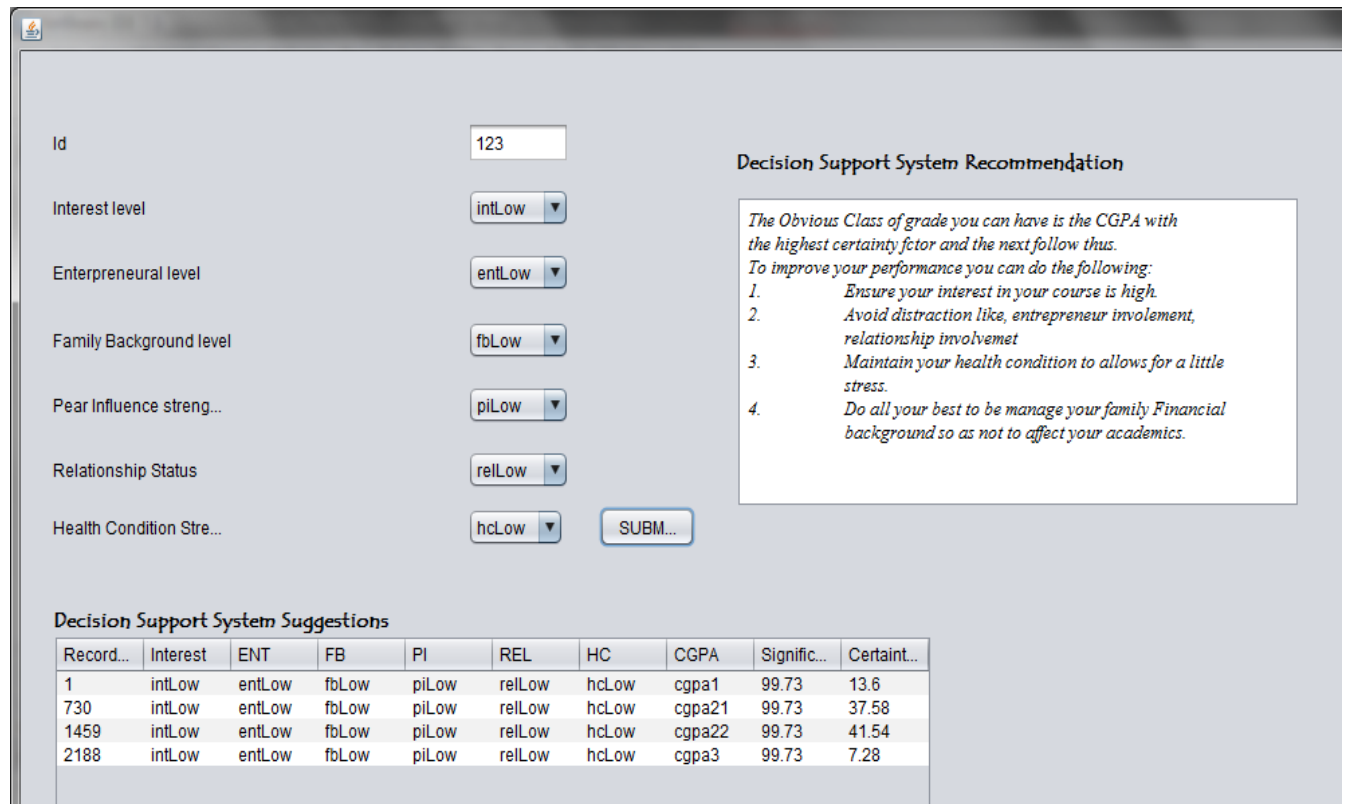

Figure 8. The Snapshot of the System User Graphical Interface 


\section{Discussion}

In Figure 8, an instance of students' query was demonstrated. This shows a student with Interest value: Low, Entrepreneur activity: low, Family background level: low, rate of pear influence: low, Relationship status: low and the health condition: low. These indicate that this student does not have interest in the course of study, is not involved in any entrepreneurial activity, his family background level is less than average, is not easily influenced by pears, is not in any serious relationship and does not have enough strength to withstand stress because of his health condition. The Decision Support System was able to suggest possible chances based on the student's involvement in the socio-economic factors. The result shows that the certainty factor for Second Class lower is $41.5 \%$ followed by Second Class upper with $37.5 \%$. This implies that, the certainty of graduating with Second Class lower is high for this type of student. Nevertheless, according to the recommendation, if this student shows more interest in the course of study and manages his health condition to allow for little stress, he might end up with Second Class upper but not First Class or Third Class grade. The certainty factor for First Class is $13.8 \%$ and Third Class is $7.28 \%$. This system provides for a quick selfevaluation in preparation for a new academic semester. It provides students with appropriate information that can support their decisions in regard to the impact of these socio-economic factors on their academic performance.

\section{System Evaluation}

The international Organization for standardization (ISO) 9241-11 defines the usability of a product as "the extent to which the product can be used by specified users to achieve specified goals with effectiveness, efficiency, and satisfaction in a specified context of use".

Usability factors were considered to know users' perception on usage of the system. The factors considered were: userfriendliness, learnability, easeofuse and satisfaction with dependent variable usability. A questionnaire was created using a Likert five point scale, where "1" represented "strongly agree", "2" for Agree, "3" for "undecided", "4" for disagree and " 5 " for "strongly Disagree". Copies of the questionnaire were distributed to 26 users; 20 responses were used while other six were voided due to missing information. Based on the factors, 8 hypotheses were deduced. The regression analysis was carried out to estimate the relationship between variables. From the analysis, it can be concluded that based on the four factors (independent variables) considered, ease of use best predicts the usability of the system. Ease of use of the system is statistically significant as 0.047 ( $\mathrm{p}<$ $0.05)$. Also, considering all the factors, the system is statistically significant at 0.035 $(\mathrm{p}<0.05)$.

\section{Conclusion}

In this study, fuzzy mining approach has been validated for building student decision support system for determining the joint effect of Students' interest, Relationship status, Entrepreneurial activities, Peer influence, Health and family background as socioeconomic factors on students' academic performance. The traditional Decision support system architecture was enhanced in the study with Fuzzy engine and Mining Engine to capture the intra-uncertainty of the domain experts and to extract hidden and previously unknown interesting knowledge. This knowledge is used to enhance students' decision based on their involvement in the socio- economic factors considered in order to minimise poor academic performance. Also, this approach was able to alleviate the limitation of statistical analysis by extracting hidden patterns from the data set. These patterns were able to reflect the extent or the degree of the impact using fuzzy concept. It also built a decision support system based on the patterns to enhance students' awareness of the effect 
of these factors on their academic. A student can confidently run a personal check on their involvement in these factors. The system will suggest the effect of their involvement and advice appropriately. The system was evaluated for usability and reliability, and found usable and reliable. For further study a more controlled system can be adopted for data gathering and a higher level of fuzzy might be considered in formulating the fuzzy models, where different experts opinion can be considered.

\section{References}

[1] M. C. Agarana, and A. I. Ehigbochie, "Optimization of Student's Academic Performance in a WorldClass University Using Operational Research Model”, International Journal of Mathematics and Computer Applications Research, vol. 5, (2015), pp.43-50.

[2] M. M. A. Shah, A. L. Farida, and A. A. Syed, "The Effects of Examination Assessment on Education by the Registered Science Teachers of Secondary Board of Education in Sindh", Interdisciplinary Journal of Contemporary Research in Business, vol. 1, no. 8, (2011).

[3] O. Oladipupo, O. Daramola, J. Oyelade, and I. Afolabi, "Analysis of the Effect of Class Attendance on Students "Academic performance Using Association rule mining technique", International Conference on Education and New Learning Technologies, Barcelona, Spain, (2014), pp.4079 - 4083.

[4] B. S. Adegoke, "Impact of Attendance on Students' Academic Performance in ICT Related Courses: Faculty of Engineering, Osun State Polytechnic, Iree”, Journal of Education and Practice, vol. 4, (2013), pp. 16

[5] D. C. Okioga, "The Impact of Students' Socio-economic Background on Academic Performance in Universities, a Case of Students in Kisii University College”, American International Journal of Social Science, vol. 2, (2013) sp. 2.

[6] D. L. Nomusa C. Cele, A. F. Botha, and, R. Metelerkamp, "A Decision Support System for Wool Classification", AUTEX Research Journal, vol. 9, (2009), pp. 2

[7] G. Sebastein, "Knowledge-Based Decision Support for Production Optimization and Quality Improvement in the Electronics Industry". OULU university press, (2006).

[8] E. Turban, "Decision Support Systems and Expert Systems" Englewood Cliff.NJ: Prentice Han, (1995).

[9] A. Y. Muhammed and O. B. Akanle, "Socio-Economic Factors Influencing Students' Academic Performance in Nigeria: Some Explanation from a Local Survey", Pakistan Journal of Social Sciences, vol. 5, (2008), pp. 319-323.

[10] A. Bayat, W. Louw, and A. R. Rena, "The Impact of Socio-economic Factors on the Performance of Selected High School Learners in the Western Cape Province, South Africa", (2014), pp. 183-196.

[11] M. O. S. Olayiwola, F. Oyenuga, J. O. Oyekunle, A. Ayansola and T. O. Agboluaje, "Statistical Analysis of Impact of Socio-Economic Factors on Students' Academic Performance”, IJRRAS, vol. 18, no. 3, (2011), pp. 18.

[12] M. H. Bornstein and R. H. Bradley, "ttps://www.questia.com/library/104786122/socioeconomic-statusparenting-and-child-development", (2003).

[13] C. W. Muller and T. L. Parcel, "Measures of Socioeconomic status: Alternatives and Recommendations", Child Development, vol. 52, no. 1, (1981), pp. 13-30.

[14] E. Tomul, and G. Polat, "The Effect of Socioeconomic characteristics of Students on their Academic Achievement in Higher Education”, American Journal of Education Research, (2013), pp. 449 - 455.

[15] E. Tomul and H. S. Savasci, "Socioeconomic determinants of academic achievement" Educational Assessment, Evaluation and Accountability, Springer, vol. 24, no. 3, (2012), pp. 175-187.

[16] M. A. Ushie, J. O. Emeka, G. I. Ononga, and E. O. Owolabi, 'Influence of Family Structure on Students' Academic Performance in Agege Local Government Area, Lagos State, Nigeria", European Journal of Educational Studies, no. 2, (2012), pp.4.

[17] O. Adesehinwa, "Effects of family type (monogamy or polygamy) on udents' academic achievement in Nigeria", International Journal of Psychology and Counselling, vol. 5, no. 7, (2013), pp. 153-156.

[18] V. Ramesh, P. Thenmozhi and D. Ramar, "Study of influencing factors of academic performance of students: A data mining Approach", International Journal of Scientific \& Engineering Research, ISSN $2229-5518$, vol. 3, no. 7, (2012).

[19] C. Pimpa, "Study of Factors Analysis Affecting Academic Achievement of Undergraduate Students in International Program", Proceedings of the International Multi Conference of Engineers and Computer Scientists, Hong-kong, vol. 1, (2013), pp.1.

[20] O. O. Oladipupo, J. O. Oyelade and D. O. Aborisade, “Application of Fuzzy Association Rule Mining for Analysing Student Academic Performance”, International Journal of Computer Science, vol. 9, no 3, (2012), pp. 3 .

[21] J. Han and M. Kamber, "Data Mining : Concept and Techniques", Elsevier. ISBN 13:978-1-55860-9013, (2006).

[22] T. Mohsen and R. Dennick, "Making Sense of Cronbach Alpha", International Journal of Medical Education, (2011), pp. 253-255. 


\section{Appendix 1}

\section{Students' Performance Survey}

Dear Respondent,

The aim of this survey is to analyze students' performance and how some socioeconomic factors can influence the aforementioned. Your involvement in this survey will be greatly appreciated. Please provide your answers by ticking as appropriate. Thank you.

1. Sex: ( ) Male; ( ) Female

2. Age (years):

3. CGPA:

\section{SD - Strongly Disagree D - Disagree U - Undecided A - Agree SA - Strongly Agree}

\begin{tabular}{|c|c|c|c|c|c|}
\hline FACTORS & SD & $\mathbf{D}$ & $\mathbf{U}$ & $\mathbf{A}$ & $\mathbf{S A}$ \\
\hline \multicolumn{6}{|l|}{ INTERESTS } \\
\hline \multicolumn{6}{|l|}{$\begin{array}{l}\text { 1. I am interested in schooling or education in } \\
\text { general }\end{array}$} \\
\hline 2. I love my course & & & & & \\
\hline 3. I am active in class & & & & & \\
\hline 4. I love being in early for class & & & & & \\
\hline \multicolumn{6}{|l|}{ 5. I chose this course by myself } \\
\hline \multicolumn{6}{|l|}{ ENTERPRENEURIAL INVOLVEMENT } \\
\hline \multicolumn{6}{|l|}{ 6. I am an entrepreneur } \\
\hline \multicolumn{6}{|l|}{ 7. I engage in it while in school } \\
\hline \multicolumn{6}{|l|}{ 8. I have had to 'miss' classes for it } \\
\hline \multicolumn{6}{|l|}{ 9. I have passion for it } \\
\hline \multicolumn{6}{|l|}{ 10. I do it because of money } \\
\hline \multicolumn{6}{|l|}{ FAMILY BACKGROUND } \\
\hline \multicolumn{6}{|l|}{ 11. I am not from a polygamous home } \\
\hline \multicolumn{6}{|l|}{ 12. I live with my both parents } \\
\hline \multicolumn{6}{|l|}{ 13. My parents respond urgently to my needs } \\
\hline \multicolumn{6}{|l|}{ 14. Issues from home disturb me } \\
\hline \multicolumn{6}{|l|}{ 15. I love being at home all the time } \\
\hline \multicolumn{6}{|l|}{ PEER INFLUENCE } \\
\hline \multicolumn{6}{|l|}{ 16. I love doing what my friends do } \\
\hline \multicolumn{6}{|l|}{ 17. I and my friends study together } \\
\hline \multicolumn{6}{|l|}{ 18. I hang out with my friends all the time } \\
\hline \multicolumn{6}{|l|}{ 19. My friends and I are on the same grade level } \\
\hline \multicolumn{6}{|l|}{ 20. I am not independently minded } \\
\hline \multicolumn{6}{|l|}{ RELATIONSHIP } \\
\hline \multicolumn{6}{|l|}{ 21. I am in a relationship } \\
\hline \multicolumn{6}{|l|}{$\begin{array}{l}\text { 22. I love hanging } \\
\text { boyfriend/girlfriend }\end{array}$} \\
\hline \multicolumn{6}{|l|}{$\begin{array}{l}\text { 23. My boyfriend/girlfriend is in the same } \\
\text { department as I am }\end{array}$} \\
\hline \multicolumn{6}{|l|}{$\begin{array}{l}\text { 24. I emotionally breakdown emotionally when } \\
\text { we have misunderstandings }\end{array}$} \\
\hline \multicolumn{6}{|l|}{ 25. We study together always } \\
\hline HEALTH & & & & & \\
\hline 26. I have a special medical history & & & & & \\
\hline
\end{tabular}




\begin{tabular}{|l|l|l|l|l|l|}
\hline $\begin{array}{l}\text { 27. I have had to miss classes as a result of my } \\
\text { ill-health }\end{array}$ & & & & \\
\hline $\begin{array}{l}\text { 28. I have had to go home and missed exams for } \\
\text { it }\end{array}$ & & & & & \\
\hline $\begin{array}{l}\text { 29. It takes a while before i get recovered from } \\
\text { my ill-health }\end{array}$ & & & & \\
\hline $\begin{array}{l}\text { 30. I have tendencies of falling sick after any } \\
\text { rigorous activity }\end{array}$ & & & & \\
\hline
\end{tabular}


International Journal of Database Theory and Application Vol.10, No.6 (2017) 